\title{
Yogures deslactosados elaborados con concentrados de leche bovina y de soja obtenidos por ultrafiltración
} Ana, N. Rinaldoni ${ }^{\S}$, Mercedes, E. Campderrós*, Antonio Pérez-Padilla*.

*Instituto de Investigaciones en Tecnología Química (INTEQUI- CONICET)

Facultad de Química, Bioquímica y Farmacia. Universidad Nacional de San Luis Argentina §e-mail: anrinald@unsl.edu.ar

(Recibido: Agosto 12 de 2009 - Aceptado: Marzo 18 de 2010)

\section{Resumen}

El objetivo del presente trabajo fue la elaboración de yogures deslactosados, a partir de concentrados de leche vacuna y de soja por tecnología de membranas. El yogur es un alimento muy nutritivo por su aporte de vitaminas, proteínas, la alta biodisponibilidad de calcio y otros nutrientes esenciales. Sin embargo, el azúcar presente en la leche de vaca resulta difícil de digerir para un segmento importante de la población mundial que posee intolerancia a la lactosa, de allí la necesidad de generar alimentos aptos para ese sector. Mediante ultrafiltración de leche vacuna y de soja se obtienen retenidos de sólidos totales adecuados para elaborar yogur, debido al incremento en la concentración de proteínas, grasas y minerales asociados y por la reducción en el contenido de lactosa u oligosacáridos y anti nutrientes que pemean a través de la membrana. En comparación con productos comerciales, el yogur obtenido a partir del concentrado de leche presenta un aumento de proteínas del $37 \%$ p/v y una disminución del 32\% p/v de lactosa. En cuanto al de soja tiene un incremento de proteínas del 16\% de p/v. La concentración de grasas en ambos yogures produce una mayor palatabilidad y suavidad. Los alimentos elaborados tienen aroma y gusto agradables y presentan un alto valor agregado por ser aptos para personas con intolerancia a la lactosa

Palabras Claves: Ultrafiltración, Concentrados de leche y soja, Yogures deslactosados.

\section{Yogurt with low lactose content elaborated with bovine milk and soymilk concentrates obtained by ultrafiltration}

\begin{abstract}
The aim of the present work was the elaboration of low lactose content yogurts using bovine milk and soymilk concentrates obtained by membrane technology. Yogurt is a very nourishing food due to its contribution of vitamins, proteins, high bio availability of calcium and essential nutrients. Nevertheless, sugar present in the bovine milk is difficult to digest for an important sector of the population that have lactose intolerance. Hence the need to generate suitable food for this sector. By ultrafiltrating bovine and soymilk, it is possible to obtain retentates with a content of total solids appropriate for developing a low lactose yogurt, due to the increase in the concentration of protein, fat and associated minerals and the removal of lactose, oligosaccharides and antinutrients which permeate through the membrane. In comparison to commercial products, the yogurt obtained from the concentrate of bovibe milk presents an increase of proteins of $37 \% \mathrm{w} / \mathrm{v}$ and a decrease of $32 \% \mathrm{w} / \mathrm{v}$ of lactose. The yogurt obtained from soymilk concentrates had an increase of proteins of $16 \% \mathrm{w} / \mathrm{v}$. The concentration of fats in both yogurts produces a major palatability and smoothness. The product has an agreeable aroma and taste and presents a high added-value for being suitable for people with lactose intolerance.
\end{abstract}

Keywords: Ultrafiltration, Concentrates of milk and soy, Yogurts with low lactose content. 


\section{Introducción}

La lactosa es el azúcar que se encuentra en forma natural en la leche. Para digerirla, el organismo humano precisa de la enzima lactasa que se produce normalmente en la mucosa intestinal, y que transforma la lactosa en unidades más pequeñas (glucosa y galactosa). La intolerancia a la lactosa se debe a la disminución o ausencia de lactasa en el tracto digestivo, esta deficiencia puede ser congénita, por un error del metabolismo en el que esta enzima falta desde el nacimiento, o adquirida. Esta última puede ser parcial o total y puede iniciarse en la infancia, adolescencia o en la edad adulta, Heyman (2006). En algunos casos puede deberse a una disminución progresiva de lactasa en las células de la mucosa intestinal a partir de los dos o tres años de edad, sin que se conozca la causa, o como consecuencia de una agresión a la mucosa intestinal por un virus, bacteria, antibióticos, quimioterapia, diarreas infecciosas, enfermedad inflamatoria intestinal crónica, enfermedad celíaca, ingesta excesiva de alcohol, etc., Sahi \& Scand(1994).

La frecuencia de intolerancia a la lactosa varía entre las distintas poblaciones, se estima que existen entre 30 y 50 millones de norteamericanos con intolerancia a la lactosa, en Japón es casi del $100 \%$, en las Islas Británicas del $24 \%$, en la población afroamericana del 45 al 81\%, China el 93\%, Europa y Australia presentan un promedio del 5\%, respecto a América Latina no se encuentran datos precisos, Brummer et al. (1993), Somkuti Somkuti \& Holsinger, (1997), Enattah et al. (2002).

Los productos lácteos constituyen una importante fuente nutricional por su aporte de vitaminas, proteínas y calcio, por lo que evitar el consumo de los mismos puede traer aparejado enfermedades tales como la osteoporosis, Flynn (2003), Cashman (2006). Dentro de los productos lácteos, el yogur ocupa un lugar destacado ya que constituye la fuente más importante de calcio biodisponible en nuestra dieta, Closa et al. (2003), De la Fuente et al. (2003).

Una alternativa a este problema es la elaboración de yogures deslactosados a partir de la fermentación de concentrados obtenidos con tecnología de membrana de leche vacuna, Álvarez et al. (1998), Rinaldoni et al. (2009a) o bien, de otra fuente vegetal que no contiene ese azúcar, como la soja, Liu et al. (1989), Messina et al. (2002), Chove etal. (2007).

El fraccionamiento mediante tecnología de membranas, principalmente la microfiltración y la ultrafiltración, consiste en la separación de una corriente en dos fracciones sobre la base del tamaño molecular o de partícula, que permite a las especies pequeñas pasar a través de la membrana mientras que las más grandes son retenidas, Cheryan (1986), Brans et.al (2004). Mediante este proceso se ha logrado obtener un concentrado con el contenido de sólidos requeridos a partir del cual se elaboran yogures con características especiales, Krishna Kumar et al. (2004), Alibhai et al. (2005), Rinaldoni et al. (2009a). Por otra parte se evitan los tratamientos térmicos de evaporación y/o agregado de leche o lactosuero en polvo que es la forma más habitual para lograr la concentración industrial de la leche destinada a la producción de yogur, Gurr (1987), Álvarez et al. (1998).

Experiencias previas indican que en el caso del alimento de soja la ultrafiltración permite la concentración de proteínas de alta calidad que tienen la capacidad de reducir los triglicéridos y el colesterol (colesterol total, colesterol-LDL y colesterol-VLDL). También se concentran las grasas que son los ácidos grasos poliinsaturados esenciales, fundamentalmente linoleico, linolénico y araquidónico, Genovese \& Lajolo (2002), Messina et al. (2002), Singh (2002). Por otra parte la membrana no retiene oligosacáridos, y anti-nutrientes que contiene la soja incluyendo ácido fítico que son eliminados en la corriente de permeado. El ácido fítico, se une a los minerales impidiendo su absorción (especialmente zinc, calcio y magnesio) y disminuye la solubilidad de las proteínas. Si bien pequeñas cantidades de estos anti-nutrientes quedan en el concentrado, luego son desactivados por la fermentación, esto es independiente del modo en que se realiza la concentración de proteínas, Omosaiye \& Cheryan (1979), Fairweather Tait (1983), Thomas et al. (2001), Krishna Kumar et al. (2004).

En este trabajo se investiga el uso de la MF y UF para obtener concentrados proteicos de leche de 
vaca y de soja para la elaboración de productos fermentados ricos en proteínas y nutrientes y con bajo o nulo contenido de lactosa. Se analizó el efecto del factor de concentración empleado y se determinaron propiedades fisicoquímicas $\mathrm{y}$ organolépticas

\section{Metodología}

\subsection{Materias primas}

Se utilizó leche parcialmente descremada (5\% lactosa, $1.5 \% \mathrm{p} / \mathrm{v}$ de grasas, $3.5 \% \mathrm{p} / \mathrm{v}$ proteínas, $10.3 \% \mathrm{p} / \mathrm{v}$ sólidos totales y $0.7 \% \mathrm{p} / \mathrm{v}$ cenizas), suministrada por la industria Argentina MILKAUT S.A, la cual fue esterilizada, homogeneizada y fortificada con vitaminas A y D en fábrica. Además se trabajó con alimento de soja comercial ADES (industria Argentina), (3\% azúcares, $1 \% \mathrm{p} / \mathrm{v}$ de grasas, $3.2 \% \mathrm{p} / \mathrm{v}$ proteínas, $8.9 \% \mathrm{p} / \mathrm{v}$ sólidos totales y $0.6 \% \mathrm{p} / \mathrm{v}$ cenizas). Se utilizó un volumen de $3 \mathrm{~L}$ como solución de alimentación en cada experiencia.

\subsection{Filtración con membrana: Microfiltración- Ultrafiltración}

Las experiencias de filtración se realizaron con el equipo esquematizado en la Figura 1. Las soluciones de alimentación (leche de vaca o de soja) se encuentran en un recipiente dentro de un baño termostático (Haake, USA), asegurando la estabilidad de la temperatura seleccionada, y son impulsadas por medio de una bomba de velocidad variable(General Electric, USA).
La alimentación se bombea a través de un filtro frontal de microfiltración de polietileno (Pall Corporation, USA), de 5-10 micrones. Esta operación reduce la cantidad de bacterias y esporas, actuando como una pasteurización en frío de la alimentación. Además, protege a la membrana de UF del ensuciamiento dado que las grasas son parcialmente retenidas por el filtro, siendo éstas una de las principales causante del ensuciamiento de la membrana, Brans et al. (2004), Rinaldoni et al. (2009a), El filtro fue limpiado y desinfectado después de cada experimento e intercambiado periódicamente.

El módulo de ultrafiltración consta de un sistema Millipore PELLICON, compuesto de capas de membranas de polisulfona, presentadas en forma de láminas apiladas con un tamiz separador de polipropileno. El corte de peso molecular es de 10 $\mathrm{kD}$, el área superficial efectiva de membrana es de $0.47 \mathrm{~m}^{2}$, tiene la ventaja de un gran área de transferencia en un pequeño volumen. Este corte de peso molecular produce un concentrado tanto de materia grasa, como de proteínas, ambos componentes necesarios para obtener la textura y viscosidad apropiada del yogur, Domagala \& Kupiec (2003), Krishna Kumar et al. (2004). El equipo consta de dos sensores de presión, para controlar las presiones de alimentación (entrada) y de concentrado (salida). La presión experimental está determinada por la presión de transmembrana $(\Delta \mathrm{P})$ definida por la Ecuación(1):

$$
\Delta P=\frac{P_{(\text {alim })}+P_{(\text {conc })}}{2}-P_{(\text {perm })}
$$

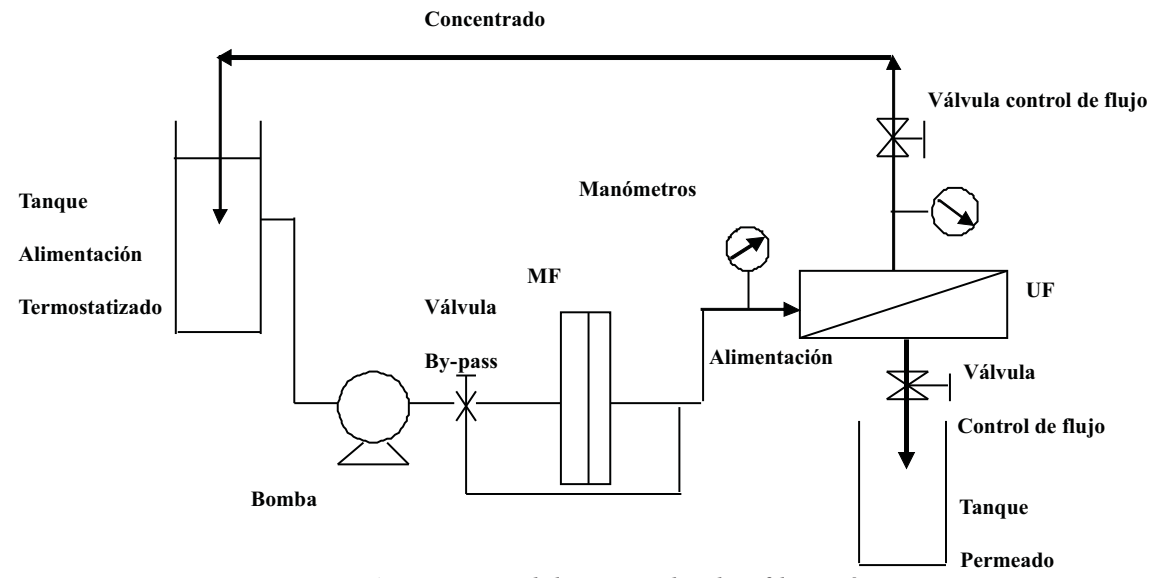

Figura 1. Esquema del equipo de ultrafiltración 
donde $\left(\mathrm{P}_{\text {alim }}\right)$ presiones a la entrada de la alimentación y $\left(\mathrm{P}_{\text {conc }}\right)$ a la salida del concentrado y $\left(\mathrm{P}_{\text {perm }}\right)$ es la presión de permeado, la cual se considera cero a menos que el permeado sea controlado por una segunda bomba.

El flujo de permeado se determinó midiendo el volumen del filtrado recogido durante un cierto período de tiempo. Las condiciones operacionales fueron $\mathrm{P}_{\text {(alim) }}=1.5$ bar y $\mathrm{P}_{\text {(conc) }}=0.5$ bar obteniendo por la Ec. (1) $\Delta \mathrm{P}=1$ bary temperatura $25 \pm 1^{\circ} \mathrm{C}$.

Después de cada filtración la membrana se limpia en línea de acuerdo con las instrucciones proporcionadas por el fabricante. El protocolo utilizado fue agua destilada - $\mathrm{NaOH}(\mathrm{pH}: 11.5 \pm$ 0.5 ) - agua destilada, cada paso se realiza a $40 \pm 2^{\circ}$ $\mathrm{C}$ durante 30 minutos, se llevó a cabo una etapa de limpieza con $\mathrm{NaClO} 300$ ppm a la misma temperatura y presión para garantizar la desinfección y un último enjuague de agua. La permeabilidad hidráulica de la membrana siempre fue recuperada, con la cual se comprobó que el procedimiento de limpieza fue realizado correctamente.

La concentración de las materias primas por UF se llevó a cabo eliminando continuamente el flujo de permeado, y el proceso se detuvo cuando se logró la concentración deseada. Ésta se determinó a través del factor de concentración (VCR), definido por la Ecuación (2), Cheryan (1986):

$$
\mathrm{VCR}=\frac{\begin{array}{c}
\text { Volumen inicial de } \\
\text { alimentación }
\end{array}}{\text { Volumen del concentrado }}
$$

La temperatura, la velocidad de recirculación, presión transmembrana, el $\mathrm{pH}$ y el flujo de permeado fueron controlados en forma sistemática.

\subsection{Análisis}

Las materias primas, concentrados, permeados y los productos fermentados fueron analizados por duplicado según los métodos estándares (Código Alimentario Argentino (CAA) y AOAC). El pH fue medido usando un peachímetro Orion digital modelo 720A (USA). La acidez fue determinada por titulación con $\mathrm{NaOH} 0.1 \mathrm{~N}$ y expresada como por ciento del ácido láctico (AOAC 15004). El contenido de sólidos totales se determinó por diferencia de peso, empleando una estufa de secado a $70 \pm 1^{\circ} \mathrm{C}$, (AOAC 15014).

Para la determinación de cenizas, las muestras fueron colocadas en crisoles de porcelana e incineradas en un horno de mufla (Indef modelo 132, Argentina) con un programador de temperatura para alcanzar $\operatorname{los} 520^{\circ} \mathrm{C}$ (AOAC 15016). El contenido proteico total fue calculado por la determinación del nitrógeno total por el método de Kjeldahl usando un Digestor de 6 Plazas (Selecta S.A, España), y un Destilador Kjeldahl Semiautomático (Selecta S.A, España), (AOAC 15017). La proporción de grasas fue medida con el método de Rosse-Gottlieb (AOAC 15029). El contenido de lactosa se determinó por el método de Cloramina-T (Norma Argentina IRAM 14001).

\subsection{Etapa de fermentación}

Los concentrados obtenidos a partir de la UF de leche de vaca y de soja fueron fermentados para obtener los yogures empleando los microorganismos Streptococcus Thermophilus y Lactobasillus Bulgaricus (Yo - Flex, YF-L702, Argentina). Dado que la leche de soja es naturalmente más baja en azúcares simples que la leche de vaca, necesita la adición de estos compuestos para que pueda fermentar adecuadamente, Wallace (1971). Los azúcares empleados en el presente estudio fueron: glucosa (Parafarm), sacarosa (Analar) y fructosa (Mallinckrodt) al 4\%(p/v). Las muestras se pausterizaron colocándolas en frascos esterilizados y calentadas a $90 \pm 1^{\circ} \mathrm{C}$ durante 30 segundos, luego se homogeneizaron, se enfriaron a $38 \pm 0.2{ }^{\circ} \mathrm{C}$, y fueron inoculadas con $20 \mathrm{ml}$ del fermento y se mantuvieron a $40 \pm 0.2^{\circ} \mathrm{C}$.

Durante la etapa de fermentación se estudió el desarrollo de la acidez (en términos de $\mathrm{pH}$ y porcentaje de ácido láctico). Cuando el producto alcanzó un $\mathrm{pH}$ entre 4.2 y 4.6 , el proceso se detuvo por refrigeración a $4-8^{\circ} \mathrm{C}$.

Los diagramas de los procesos de elaboración de yogures deslactosados se esquematizan en la 


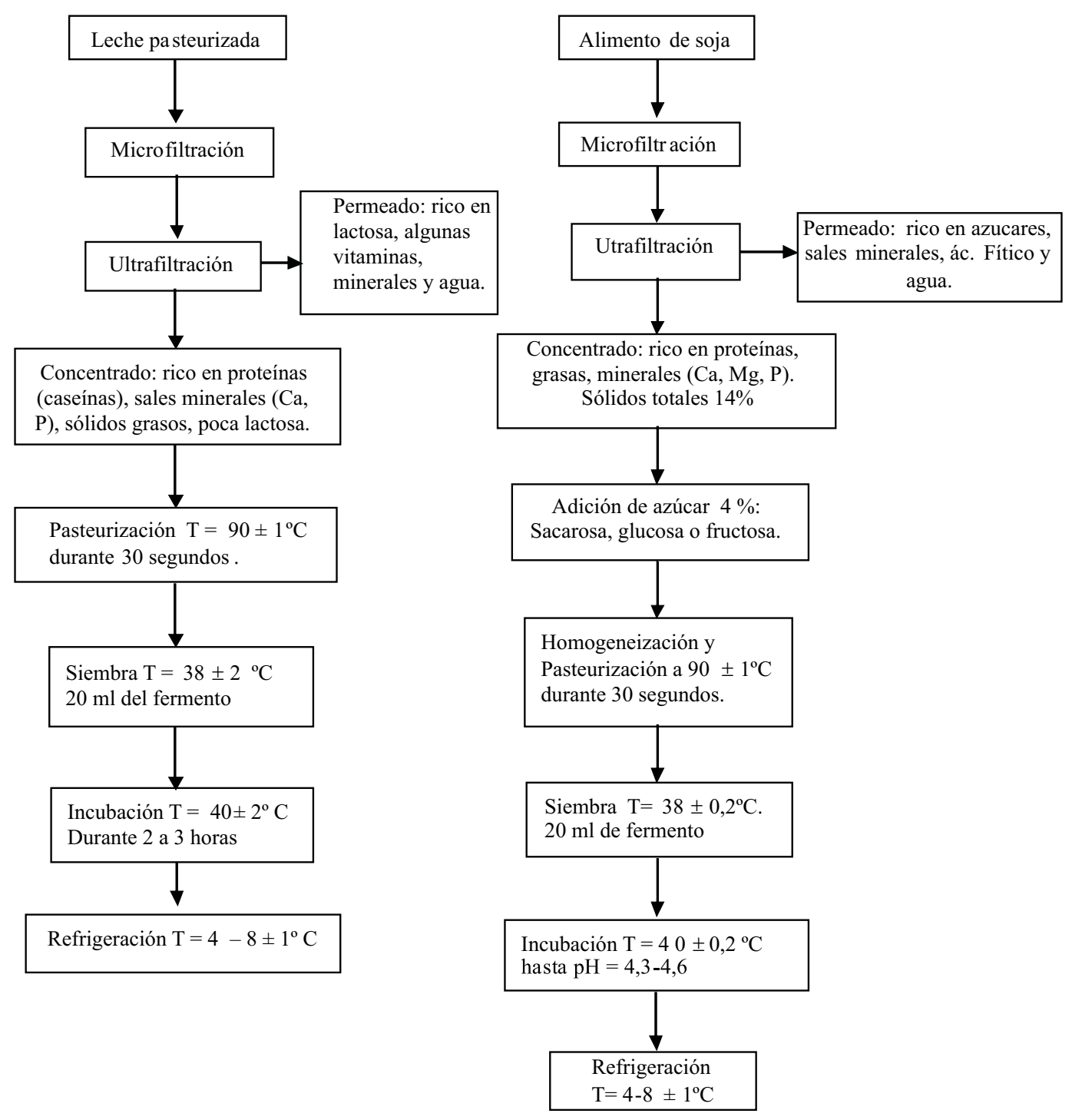

Figura 2. Esquema de los procesos de fabricación de yogures deslactosados.

Figura 2. Además de los análisis mencionados, los productos fermentados fueron evaluados por medio de las siguientes determinaciones: viscosidad, porcentaje de sinéresis y evaluación sensorial.

La viscosidad se midió con un viscosímetro rotacional Haake VT02, (Alemania), (con tres rotores intercambiables, a $22 \pm 5{ }^{\circ} \mathrm{C}$ ). $\mathrm{La}$ determinación de sinéresis se llevó a cabo después de 24 horas de almacenamiento en frío a $4{ }^{\circ} \mathrm{C}$. Las muestras se agitaron durante $60 \mathrm{~s}$ en una plataforma de agitación y a continuación se centrifugaron durante 25 minutos a 5,000 rpm en una ultracentrífuga, Beckman J2 - HS (USA) a $4{ }^{\circ} \mathrm{C}$. El porcentaje de sinéresis, $\mathrm{S} \%(\mathrm{p} / \mathrm{p})$ se calculó a partir de la Ecuación. (3), Aichinger et al. (2003):

$$
S \%=\frac{m(\text { suero })}{m(\text { gel })} 100
$$


donde, $m$ (suero) es la masa de suero que se ha separado del gel debido a la centrifugación, en relación con $m$ (gel) la masa total del gel que fue centrifugada.

Se realizó un análisis sensorial de los yogures mediante una técnica de comparación clasificándolas entre sí por preferencia global, Lawless (1998). Las muestras fueron evaluadas por tres grupos de 30 jueces no entrenados. El análisis consistió en probar tres muestras con características sensoriales similares como olor, color, textura, sobre las cuales debían decir cuál era el más agradable a su criterio. Luego con los datos obtenidos se realizó un análisis estadístico mediante el test de la varianza (ANOVA), sobre los tres grupos y sus correspondientes réplicas, considerando estadísticamente significativo un P0.005.

\section{Resultados y Discusión}

\subsection{Concentrados por MF-UF}

Los perfiles de flujo de permeado obtenidos en la ultrafiltración muestran una caída característica en los primeros 10 minutos, seguido por una tendencia hacia el estado estacionario, Figura 3. i-
Estudios previos han demostrado la presencia de una serie de fenómenos que actúan simultáneamente reduciendo el flujo de permeado. Cronológicamente es posible identificar tres fases de disminución de flujo. En los primeros minutos la caída del flujo es rápida lo cual se debe principalmente a la polarización por concentración. En la segunda fase, el flujo sigue disminuyendo, al principio con rapidez debido a la deposición de proteínas. Es probable que se forme inicialmente una monocapa de adsorción y que, en el transcurso de la operación de UF, se forme una capa completa sobre la superficie de la misma debido a la deposición de proteínas. La tercera fase, es un periodo cuasi-estado de equilibrio en donde el flujo disminuye lentamente, esto puede deberse a la deposición de partículas o por la consolidación de la capa de ensuciamiento, Marshall et al. (1993); Atra et al. (2005); Rinaldoni, et al. (2009b).

El hecho es que, además de la disminución del flujo, la retención de proteínas en general, aumenta con el tiempo, Attia et al. (1991). A pesar del decaimiento del flujo de permeado luego del proceso de MF-UF, comparando los costos con los métodos tradicionales de concentración, indica un potencial ahorro significativo en los costos de operación, Belhocine et al. (1998). Comparando los resultados con procedimientos informados por Brazuelo et al. (1995), quienes emplean la UF

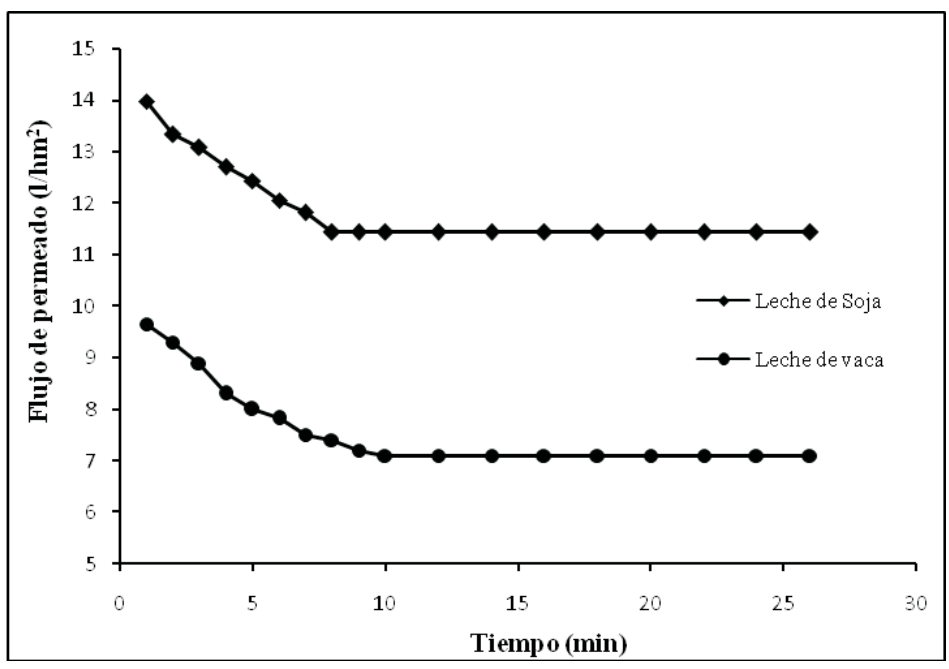

Figura 3. Flujo de permeado en función del tiempo. $\left(\mathrm{T}=25 \pm 2{ }^{\circ} \mathrm{C}, \Delta \mathrm{P}=1 \pm 0.05\right.$ bar $)$. 
Tabla 1. Sólidos totales en los concentrados por UF de leche y de soja. ( $T=25 \pm 2{ }^{\circ} \mathrm{C}$ y $\Delta P=1 \pm 0.05$ bar $)$

\begin{tabular}{ccccc}
\hline $\begin{array}{c}\text { Volumen } \\
(\mathbf{m L})\end{array}$ & VCR & $\begin{array}{c}\text { \% Volumen } \\
\text { reducido }\end{array}$ & $\begin{array}{c}\text { Sólidos totales (\% p/v) } \\
\text { Leche de Soja }\end{array}$ \\
\hline 3,000 & 1.00 & 0 & $10.32 \pm 0.20$ & $10.7 \pm 0.10$ \\
2,400 & 1.25 & 20 & $10.95 \pm 0.15$ & $11.3 \pm 0.20$ \\
2,000 & 1.50 & 33 & $12.35 \pm 0.15$ & $12.7 \pm 0.10$ \\
1,500 & 2.00 & 50 & $13.70 \pm 0.10$ & $13.8 \pm 0.15$ \\
1,200 & 2.50 & 60 & $14.50 \pm 0.20$ & $14.4 \pm 0.15$ \\
\hline
\end{tabular}

para elaborar un yogur enriquecido de proteínas a partir de leche descremada y Castro \& Gerla (2005) quienes aplicaron la UF del suero de queso con membranas de fibras huecas y espiral, nuestras experiencias, muestran que la combinación de la MF y la UF empleados en el tratamiento de las soluciones de alimentación producen un menor ensuciamiento en la membrana de ultrafiltración, reduciendo los tiempos de limpieza y aumentando el período de vida de la membrana polimérica.

Con el objeto de obtener concentrados que contengan los sólidos totales aptos para la elaboración del yogur, se llevaron a cabo experiencias a distintos factores de concentración, VCR. Los resultados se muestran en la Tabla 1. Puede observarse que el tratamiento por UF permite concentrar adecuadamente ambas materias primas, leche y alimento de soja. Se determinó que operando a un VCR entre 1.5-2.5, se obtienen concentrados adecuados para la producción de yogur (con un contenido de sólidos totales entre $12-14 \%$ según el CAA), lo que determina el punto final del proceso de concentración por UF. Estos resultados son consistentes con los previamente encontrados por Brazuelo et al. (1995) en leche bovina descremada, trabajando con membranas de $10 \mathrm{kD}$, para valores de VCR comprendidos entre 1.1 y 2.8 .

Para un VCR de 2, los análisis efectuados por duplicado en concentrados de leche mostraron un contenido de proteínas de $5.58 \pm 0.02 \% \mathrm{p} / \mathrm{v}$ y de lactosa $5.32 \pm 0.12 \% \mathrm{p} / \mathrm{v}$, dando una relación proteína/lactosa de 1.04, mientras que la materia prima contiene una relación de 0.6. Para el caso de soja, al mismo VCR, las determinaciones indicaron un contenido de proteínas de $4.6 \pm 0.05 \%$ $\mathrm{p} / \mathrm{v}$ y sin lactosa. Por otra parte, Chove et al. (2006) investigaron la concentración de proteínas de soja empleando membranas de microfiltracion $\mathrm{y}$ concluyeron que las propiedades funcionales eran mejoradas empleando tecnología de membranas en su concentración.

\subsection{Fermentación de los concentrados}

Se fermentaron los concentrados de leche y de soja de acuerdo al procedimiento descripto. En el caso de soja, el concentrado proteico obtenido por MFUF se dividió en tres porciones, y se emplearon glucosa, sacarosa y fructosa, a fin de determinar el más apropiado para el propósito buscado. Se estudió la evolución del $\mathrm{pH}$ y la acidez a intervalos de una hora durante el proceso. Los resultados se muestran en la Figura 4.

Se pudo observar que en los tres concentrados de soja se produjo adecuadamente la fermentación, y tuvieron el mismo comportamiento con respecto al concentrado de leche, donde el $\mathrm{pH}$ en la primera hora disminuyó muy poco de $6.7 \pm 0.10$ a $6.5 \pm 0.12$ en los concentrados de soja, mientras que en el concentrado de leche disminuyó de $6.5 \pm 0.10$ a 6.3 \pm 0.15 . Sin embargo, en un período de dos horas se reduce rápidamente a valores de $5 \pm 0.10$ aproximadamente, en tanto que la acidez total titulable sufre un drástico incremento de $0.13 \pm$ 0.15 a $0.3 \pm 0.20$ en los concentrados de soja y presentó un aumento de $0.18 \pm 0.10$ a $0.41 \pm 0.12$ en el concentrado de leche. Luego de tres horas el pH disminuye más lentamente en todos los casos hasta llegar al valor de $4.5 \pm 0.2$, indicado para cortar la fermentación. 


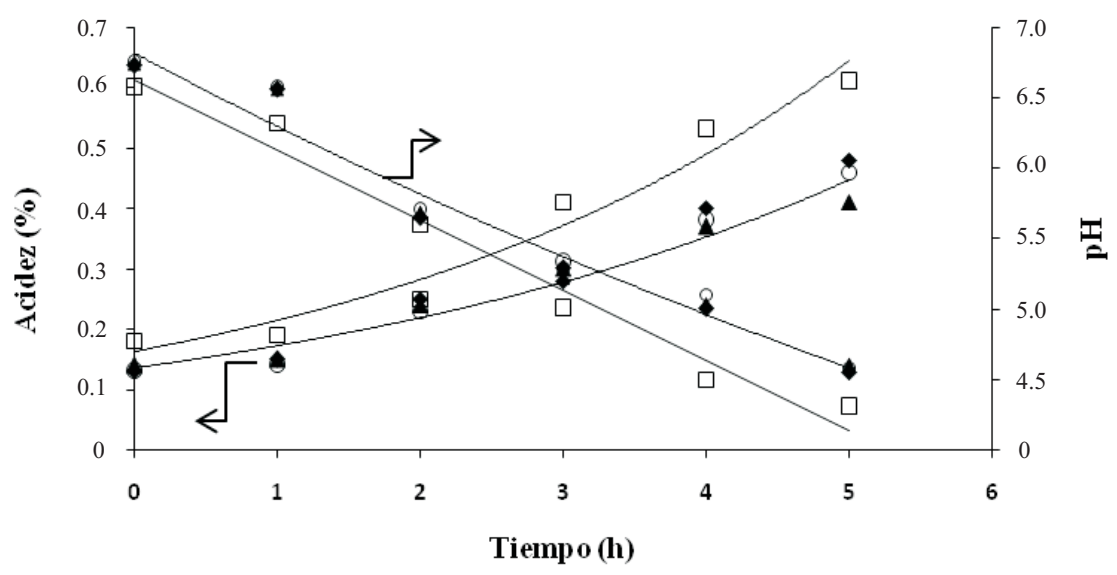

- Leche de soja + glucosa OLeche de soja+ sacarosa $\Delta$ Leche de soja + Fructosa $\square$ Leche

Figura 4. Espectro del pH y tiempo sobre la acidez durante la fermentación.

Los yogures presentan al final del proceso fermentativo, una acidez titulable de $0.45 \pm 0.05$ $\%$ (ácido láctico) en la soja y $0.61 \pm 0.10 \%$ para leche. El valor obtenido de acidez es, en cualquiera de los casos, menor que la media para productos comerciales cuyo valor es $(0.8-0.95)$, Código Alimentario (2006). En efecto, el valor de acidez esperable se desarrolla con una adecuada maduración. Para ello, los yogures obtenidos se almacenaron durante 4 semanas y se verificó el aumento de acidez con el tiempo. En el caso del yogur con leche de vaca alcanzó a los 14 días un valor final de $0.81 \pm 0.2 \%$. El yogur de soja alcanzó una acidez ligeramente inferior con el almacenamiento, $0.63 \pm 0.16$, debido a que contiene menos cantidad de azúcar, en algunos casos es necesario adicionar ácido láctico para alcanzar el valor de acidez adecuado.

Los resultados del análisis sensorial mostraron que ninguno de los productos obtenidos fue rechazado por los jueces, siendo el más aceptable el yogur fermentado con sacarosa dando un valor de $\quad \mathrm{P}<0.0001$ considerado extremadamente significativa según el test de análisis de la varianza (ANOVA). Los yogures obtenidos tenían un aroma agradable con una consistencia adecuada. La Figura 5, muestra el porcentaje de aceptación de las distintas muestras de yogur de soja, con respecto al tipo de azúcar empleado. Se puede observar que más del $50 \%$ de los jueces prefirieron la muestra fermentada con sacarosa, siendo este azúcar de uso más corriente y además, de menor costo. De éste modo se eligió estudiar las propiedades fisicoquímicas del yogur de soja fermentado con sacarosa y el yogur obtenido a partir del concentrado de leche vacuna.

Los resultados obtenidos fueron comparados con yogures de leche descremados comerciales (yogures de referencia) los cuales se muestran en la Tabla 2. El análisis de los datos muestra que los yogures obtenidos tienen mayor $\mathrm{pH}$ y menor acidez con respecto a los yogures de referencia, esto se debe a que contienen menos cantidad de azúcar (en particular el yogur de soja), por lo tanto es menor la producción de ácido láctico. E1 contenido de proteína ha aumentado un $16 \% \mathrm{p} / \mathrm{v}$ y un $37 \%$ p/v en los yogures obtenidos a partir de concentrados por UF de soja y leche respectivamente comparándolos con la referencia. También se observa un incremento del $1.650 .05 \mathrm{p} / \mathrm{v}$ de grasas en ambos yogures. Estas características hacen que estos productos sean nutricionalmente interesantes dado que son fuentes de proteínas con alto valor biológico y en el caso de la soja el contenido graso es de origen vegetal. En cuanto al contenido de lactosa el yogur obtenido por fermentación del concentrado 


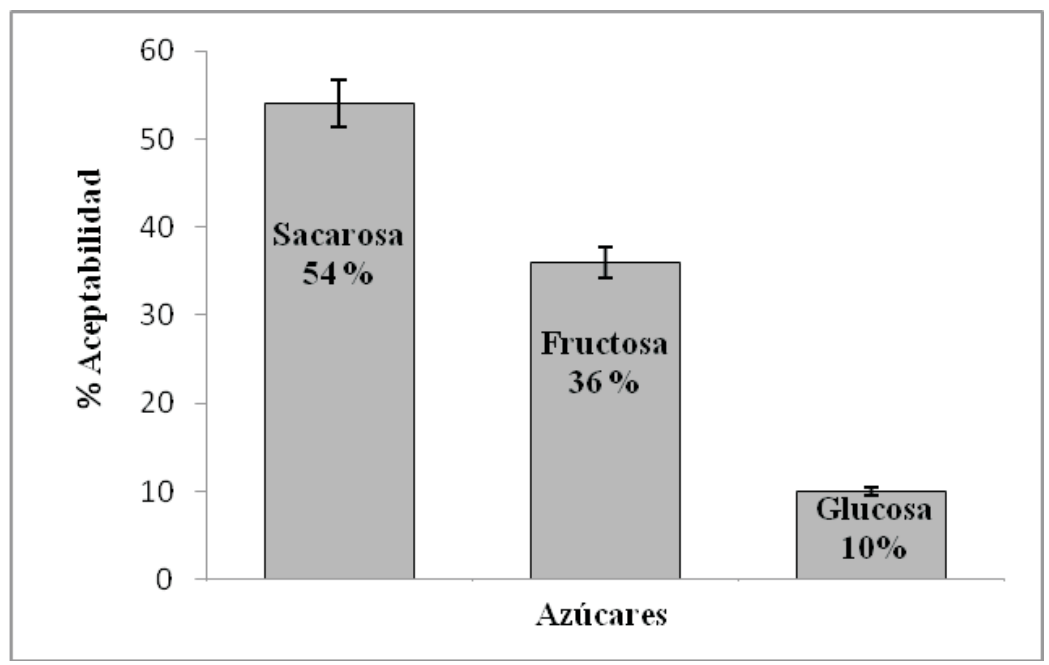

Figura 5. Resultados del análisis sensorial. Porcentaje de aceptación del yogur de soja con diferentes azúcares.

Tabla 2. Propiedades fisicoquímicas de los productos finales. (medias $\pm D S$ ).

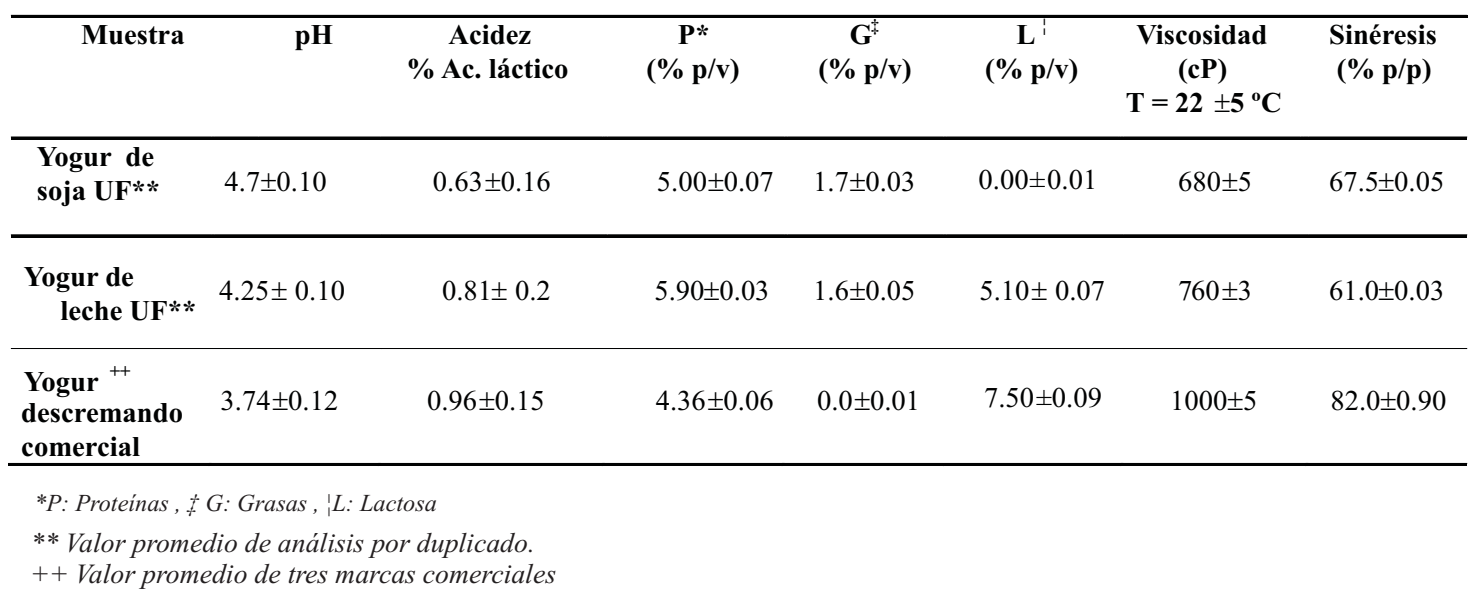

por UF de leche bovina presenta una disminución del $32 \% \mathrm{p} / \mathrm{v}$ con respecto a los yogures de referencia, mientras que el yogur de soja no contiene lactosa. Por esta razón estos alimentos resultan aptos para personas con intolerancia al mencionado azúcar.

Los resultados de las mediciones de viscosidad indicaron que las muestras tienen un comportamiento no newtoniano al igual que el yogur comercial, los valores obtenidos se encuentran dentro del rango establecido por el
C.A.A para este tipo de alimento, un poco por debajo de la determinación correspondiente a los yogures descremados comerciales evaluados.

Los resultados de sinéresis arrojaron valores menores que los obtenidos en los yogures de referencia, esto se debe al aumento en el contenido de proteínas y grasas, en concordancia con lo encontrado por Mehaia \& El-Khadragy, (1998); Keogh et al. (2003). La concentración de proteínas y grasas contribuye a lograr un coágulo muy estable, esto fue comprobado con estudios realizados a los 7 y 14 días. 


\section{Conclusiones}

Los resultados demostraron que por MF-UF se pueden obtener concentrados de leche para producir yogures deslactosados, sin el agregado de agentes externos, como por ejemplo leche en polvo o espesantes o tratamientos térmicos. La metodología aplicada en el tratamiento con membranas redujo el ensuciamiento y la membrana se pudo recuperar fácilmente manteniendo las condiciones de permeoselectividad.

Los yogures presentan un incremento marcado de proteínas, lo cual tiene un efecto buffer que suaviza la acidez y el sabor, obteniendo un producto muy aceptable. El contenido graso fue igualmente incrementado en el proceso de UF, por lo que los yogures, en comparación con los comerciales, presentaron un agradable aroma, aumento de la palatabilidad y estabilidad del coágulo, el cual presentó menor sinéresis.

Los productos elaborados a partir del concentrado de leche por MF-UF tienen un contenido en lactosa reducido un $32 \% \mathrm{p} / \mathrm{v}$ respecto a los comerciales, mientras que el yogur de soja no contiene dicho azúcar, originando un producto no tan ácido y con una mejor digestibilidad. Además evita la aparición de textura arenosa, debido a la cristalización de este azúcar.

A partir de lo mencionado, se puede concluir que los alimentos obtenidos constituyen una fuente de proteína de excelente calidad por el tratamiento aplicado en su concentración, con buenas cualidades sensoriales y que representan alternativas nutricionales para personas con intolerancia a la lactosa por el bajo o nulo contenido de éste azúcar.

\section{Referencias bibliográficas}

Aichinger, P.A., Michel, M., Servais, C., Dillmann, M-L., Rouveet, M., D'Amico, N., Zink, R., Klostermeyer, H., \& Horne, D.S. (2003). Fermentation of a skim concentrate with Streptococcus thermophilus and chymosin: structure, viscoelasticity and syneresis of gels, Colloids and Surface B Biointerfaces 31, 243255.
Alibhai, Z., Mondor, M., Moresoli, C., Ippersiel, D., \& Lamarche, F. (2005). Production of spray protein concentrates/aislates: traditional and membrane technologies. Desalination 191, 351358.

Álvarez, F., Arguello, M., Cabero, M., Riera, F.A., Álvarez, R., \& Iglesias, J.R. (1998). Fermentation of concentrated skim-milk. Effects of different Protein/lactose ratios obtained by ultrafiltrationdiafiltration. Journal of the Science of Food and Agriculture 76(1), 10-16.

AOAC. Official Methods of Análisis, International, $16^{\text {th }}$ Edition, Volumen I y II.

Atra, R., Vatai, G., Bekassy-Molnar, E., \& Balint, A (2005). Investigation of ultra-and nanofiltration for utilization of whey protein and lactose. Journal of Food Engineering, 67(3), 325-332.

Attia, H., Bennasar, M., \& Tarodo de la Fuente, B. (1991). Study of the fouling of inorganic membranes by acidified milks using scanning electron microscopy and electrophoresis. I. Membrane with pore diameter $0.2 \mu \mathrm{m}$., Journal of Dairy Research 58, 39-50.

Belhocine, D., Grib, H., Abdessmed, D., Comeau, Y., Mameri, N., (1998). Optimization of plasma proteins concentration by ultrafiltration, Journal of Membrane Science 142(2), 159-171.

Brans, G., Schroen, C.G.P.H., Van der Sman, R.G.M., \& Boom, R.M. (2004). Membrane fractionation of milk: state of art and challenges. Journal of Membrane Science 243(1), 263- 272.

Brazuelo, A., Suárez, E., Riera, F. A., Alvarez, R. (1995). Protein-Enriched Yoghurt by Ultrafiltration of Skim-Milk. Journal of the science offood and agriculture, 69(3), 283-290.

Brummer, R.J., Karibe, M., Stockbrugger, R.W., \& Scand, J. (1993). Lactose malaabsortion: Optimalization of investigational methods. Scandinavian Journal of Gastroenterology 28 (200), 65-66. 
Cashman, K.D. (2006). Milk minerals (including trace elements) and bone health. International Dairy Journal 16(11), 1389-1398.

Castro, B.N., \& Gerla, P.E. (2005). Hollow fiber and spiral cheese whey ultrafiltration: minimizing controlling resistances. Journal of Food Engineering 69(4), 495-502.

Cheryan, M. (1986). Ultrafiltration Handbook. USA: Technomic Publishing Co.

Chove, B.E., Grandison, A.G. \& Lewis, M.J. (2007). Some functional properties of fractionated soy protein isolates obtained by microfiltration. Food Hydrocolloids 21(8), 1379-1388.

Closa, S. J., Landeta, M.C., Andérica, D., Pighín, A. \& Cufré, J.A. (2003). Contenidos de nutrientes minerales en leche de vaca y derivados de Argentina. Archivos Latinoamericanos de Nutrición 53, 3 .

Código Alimentario Argentino CAA. Ley 18284/69 (2006). Capítulo VIII. Alimentos Lácteos. Argentina: La Roca. 2006.

De la Fuente, M.A., Montes, F., Guerrero, G., \& Juárez, M. (2003). Total and soluble contents of calcium, magnesium, phosphorus and zinc in yoghurts, Food Chemistry 80(4), 573-578.

Domagala, J., \& Kupiec, B.E. (2003). Changes in texture of yoghurt from ultrafiltrated goat's milk as influenced by deferent membrane types. Electronic Journal of Polish Agricultural Universities, Food Science and Technology Series $6,1-6$.

Enattah, N.S., Sahi, T., Savilahti, E., Terwilliger, J.D., Peltonen, L., \& Järvellä, I. (2002). Identification of a variant associated with adult type hypolactasia. Nature Genetic 30(2), 233-237.

Fairweather Tait, S.J. (1983). The availability of minerals in food, with particular reference to iron. The Journal of the Royal Society for the Promotion of Health 103(2), 74-77.
Flynn, A. (2003). The role of dietary calcium in bone health. Proceedings of the Nutrition Society 62, 851-858.

Genovese, M., Lajolo, F. (2002). Isoflavones in soy-based foods consumed in Brazil: Levels, distribution, and estimated intake. Journal Agricultural and Food Chemistry 50(21), 59875993.

Gurr, M I. (1987). Nutritional aspects of ferment milk products. FEMS Microbiol Rev. 46, 337-342.

Heyman M.B., (2006). Lactose intolerance in infants, children, and adolescents. Pediatrics 118 (3), 1279-1286.

Keogh, K.M., Murray, C.A., \& O'Kennedy, B.T. (2003). Effects of ultrafiltration of whole milk on some properties of spray-dried milk powders. International Dairy Journal 13(12), 995-1002.

Krishna Kumar, N.S., Yea, M.K., \& Cheryan, M. (2004). Ultrafiltration of soy protein concentrate: performance and modelling of spiral and tubular polymeric modules. Journal of Membrane Science 244(1-2), 235-242.

Lawless, H.T. (1998). Sensory evaluation offood. USA: Principles and Practices.

Liu, F. K., Nie, Y. H., Shen, B. Y., (1989). Manufacturing soy protein isolate by ultrafiltration, Proc. World Congress on Vegetable Protein Utilization in Human Foods and Animal Feedstuffs, Singapore, 84-90.

Marshall, A.D., Munro, P.A., \& Trägardh, G. (1993). The effect of protein fouling in microfiltration and ultrafiltration on permeate flux, protein retention and selectivity: A literature review, Desalination, 91(1), 65-108.

Mehaia, M.A. \& El-Khadragy, S.M. (1998). Physicochemical characteristics and rennet coagulation time of ultrafiltered goat milk. Food Chemistry, 62 (3), 257-263. 
Messina, M., Messina, V., \& Setchell, K.D.R. (2002). Beneficios de la soja para su salud. Argentina: ASAGA: Asociación Argentina de Grasas y Aceites.

Omosaiye, O., \& Cheryan, M. (1979). Ultrafiltration of soy-bean water extracts: processing characteristics and yields. Journal of Food Science 44(4), 1027-1031.

Rinaldoni, A.N., Campderrós, M.E., Menéndez, C., \& Pérez Padilla, A. (2009a). Fractionation of skim-milk by an integrated membrane process for yogurt elaboration and lactose recuperation. International Journal of Food Engineering 5, (3), Article 1.DOI: 10.2202/1556-3758.15315.

Rinaldoni, A. N., Tarazaga, C. C., Campderrós, Pérez Padilla, A., (2009b). Assessing performance of skim milk ultrafiltration by using technical parameters. Journal of Food Engineering, 92(2), 226-232.
Sahi, T. \& Scand, J., (1994). Genetic and epidemiology of adult-type hypolactasia. Scandinavian Journal of Gastroenterology. 29 (202), 7-20

Singh, N. (2002). Soy protein concentrate having high isoflavone content and process for its manufacture, United States patent US 20020197384.

Somkuti, G.A., \& Holsinger, V.H. (1997). Microbial technologies in the production of low lactose dairy foods. Food Science. and Technology International 3(3), 163-169.

Thomas, R.L., Ndife, L.I., Shallo, H., \& Nelles, L.P. (2001). Soy proteins and methods for their production, United States patent US 6313273.

Wallace, G.M. (1971). Studies on the processing and properties of soy milk. Journal of Science \& Food Agriculture 22, 526-535. 